\title{
Urdimento
}

\section{MITOPOESE, DRAMATURGIA CRIATIVA E O TRABALHO DO ATOR}

\author{
Milton de Andrade 1
}

\section{Resumo}

Neste artigo, procura-se trazer para o âmbito da pesquisa teatral conceitos próprios da psicologia simbólica com o objetivo de esclarecer o papel das funções mitopoéticas em processos criativos e no trabalho do ator. Abre-se campo para reflexões da importância da abordagem mitopoética e das funções psicológicas envoltas no trabalho teatral e na dramaturgia criativa.

Palavras-chave: mito, psicologia, teatro, dramaturgia.

\begin{abstract}
This article aims at bringing concepts from symbolic psychology to the field of theater research in order to explain the role of mythopoetic functions in creative process and in actor's work. We also reflect on the importance of a mythopoetic approach and on the psychological functions that surround a performance work and a creative dramaturgy.
\end{abstract}

Keywords: myth, psychology, theater, dramaturgy.

Configurar e reconfigurar: eterno prazer do sentido eterno. Carl Gustav Jung

A palavra mitopoese, do grego mûthopoiêis, significa literalmente “origem, criação de um mito". Walter Boechat define a mitopoese como a capacidade espontânea da psique em produzir mitos: “a psique tem a capacidade natural e espontânea de produzir imagens mitológicas, que são imagens arquetípicas, nas mais variadas situações do cotidiano [...] Os arquétipos constituem e são responsáveis pela faculdade mitopoiética da mente humana, a sua faculdade criadora de mitos.” (2008, pp. 13 e 56).

Segundo a psicologia junguiana, a mitopoese seria a capacidade da mente de recriar mitologemas em padrões culturalmente compartilhados. Os mitos nos ajudariam a fazer uso estruturado da imaginação e de nossos poderes intuitivos e seriam, também na experiência clínica através do método da amplificação ${ }^{2}$, um modo libertário de ideação e de criação de linguagem compartilhada, processos esses fundamentais no processo de individuação. Mythologein, mitologizar,
${ }^{1}$ Milton de Andrade é docente do Programa de Pós-Graduação em Teatro da Universidade do Estado de Santa Catarina (UDESC), formado em Psicologia pela Universidade de São Paulo (USP), com Mestrado e Doutorado em Artes Cênicas pela Universidade de Bolonha (Itália).

${ }^{2}$ Método próprio de Carl Gustav Jung (1875-1961) para a utilização das mitologias como

"amplificação" de uma situação existencial na técnica analítica psicoterapêutica. 


\section{Urdimento}

${ }^{3} \mathrm{~A}$ tal propósito de apropriação da mitocrítica duraniana, vide o projeto de pesquisa "Mitologia e identidade artística: uma análise da presença de mitemas heróicos nos discursos de artistas e críticos" sob orientação do Prof. Dr. Antonio Vargas Sant 'Anna e desenvolvido no Centro de Artes da UDESC, vide também SANT'ANNA, 2006.

${ }^{4} \mathrm{~N}$ o Brasil, vide, entre outros, o essencial O mito e o herói no moderno teatro brasileiro (1982) de Anatol Rosenfeld (1912-1973). criar e recriar mitos, não seria somente um modo retroativo e "nostálgico" de recuperar memórias coletivas, mas uma ação vitalizadora dos vínculos entre a contemporaneidade da vida psíquica e a tradição cultural. Como forma nãodiscursiva de produção simbólica (CASSIRER, 1985), o mito extrapola os limites do discurso lógico, do pensamento dirigido e adaptativo; é solução e ampliação de sentido para as aporias (caminhos sem saída) do logos e da razão. "Vale a dizer que o discurso, com o auxílio dos mitos, ganha a profundidade dos mistérios." (BOECHAT, 2008, p. 19).

Desde Bronislaw Malinowski (1884-1942), a antropologia do século XX ressaltou a importância dos mitos na organização da vida e na ritualização da experiência. Ritos de passagem, ritos metamórficos, ritos transicionais, mesmo no individualismo das sociedades tecnológicas contemporâneas, dependem da aderência a mitologemas como agentes simbólicos e catalisadores de mudanças socialmente compartilhadas.

Conforme define Karl Kerenyi: "O mitologema é um material mítico que é continuamente revisitado, remodelado e plasmado, como um rio de imagens sem fim" (1983, p. 15, trad. nossa). A mitologia seria o movimento compositivo deste material (mitologema), sendo assim constituída uma unidade incindível entre tal movimento de linguagem e o material primário criativo, do mesmo modo como ocorre, por exemplo, entre a linguagem musical e seu material (o mundo sonoro).

Segundo a mitocrítica de Gilbert Duran, o mitologema seria uma espécie de esqueleto da obra mitológica e o mitema a menor unidade de sentido que compõe o mito. ${ }^{3}$

Para Jung, os mitologemas são núcleos constitutivos de todo mito, "constituem expressões imagéticas dos arquétipos, que são, em si mesmos, incognoscíveis" (BOECHAT, 2008, p. 57). Representam símbolos essenciais do processo de individuação ou do desenvolvimento da personalidade. São expressões que nascem quando a função transcendente da psique gera, como solução criativa, um tertio non datur (terceiro não determinável) a partir de uma tensão de opostos irreconciliáveis. São núcleos dinâmicos essenciais que se repetem, circulam, se deslocam de mito a mito, e permitem a constante revitalização e recriação elipsóide de conteúdos simbólicos.

Qualquer estudioso de dramaturgia não teria dificuldade em verificar tais processos de revisitação de conteúdos mitológicos presentes, de forma implícita ou explícita, nas mais diversas matrizes literárias e não literárias na história do teatro ${ }^{4}$. Mythologein, no campo das artes cênicas, é ação fundamental tanto nos processos subjetivos e metamórficos da arte do ator, como na arte da composição dramatúrgica e na vitalização da recepção teatral, entendida 
como ato de compartilhamento, coletivização e questionamento de símbolos e valores humanos. O tecido dos mitos é o mesmo tecido dos sonhos e das fantasias (BOECHAT, 2008); é também o mesmo tecido dos "devaneios" poéticos teatrais. E é a associação de imagens míticas com experiências rituais que permite a emergência do mito como linguagem na cultura teatral.

De acordo com Gaston Bachelard, os mitos não são fábulas fossilizadas, mas linhas de vida e imagens do devir: "todo mito é um drama humano condensado. E é por essa razão que todo mito pode, tão facilmente, servir de símbolo para uma situação dramática atual” (BACHELARD in DIEL, 1991, p. 10), pois fala do destino humano sob seus aspectos essenciais.

Conforme nos ressalta o psicólogo francês de origem austríaca Paul Diel, a significação simbólica mítica é de ordem psicológica e prefigura uma "percepção verídica" do conflito intrapsíquico através de uma "observação íntima” capaz de pressentir as motivações que sustentam as ações humanas.

Esta observação íntima das motivações, também fundamental no trabalho do ator, é um fenômeno adaptativo elementar, pois o ser humano não pode sobreviver sem esta constante atenção para a intenção subjacente em toda atividade, "seja para controlar suas próprias ações, seja para projetar na psique de outros os conhecimentos assim adquiridos em relação às motivações humanas, com o objetivo de interpretar as intenções de seus semelhantes e assim encontrar um meio de se impor ou se defender. [...] Para orientar-se na vida, o homem deve evoluir em direção à lucidez sobre suas intenções secretas.” (DIEL, 1991, p. 20). Segundo Diel, a análise dos modos de elaboração desta "observação íntima" revela as atitudes do homem em relação à simbolização de suas motivações em termos de sublimação ou recalque: "Toda a simbolização do mito, segundo seu sentido oculto, encerra-se na análise dessa vergonha repressora e no valor da confissão sublimadora [...] O caminho do recalcamento é, de longe, a reação mais frequente nos homens, pois o amor-próprio obriga cada qual a esconder suas verdadeiras motivações, frequentemente inconfessáveis, e a ornar-se de motivações carregadas de uma sublimidade mentirosa." (DIEL, 1991, pp. 19 e 20).

Sendo as motivações falsas por justificativas afetivas e imaginárias, as ações também serão falseadas ou destorcidas por esta lógica cruel da ocultação e da ruptura da integridade das motivações, causa de sofrimento psíquico, que somente pode ser elaborado com a reparação desta interpretação equivocada das motivações. "É desse sofrimento e da necessidade de ultrapassá-lo que falam os mitos." (DIEL, 19991, p. 21). Os mitos tratam da falta essencial do homem que, devido ao amor-próprio, à "mentira orgulhosa em relação a si mesmo" e à "tendência à falsa justificação", reprime afetivamente as 


\section{Urdimento}

${ }^{5}$ Van Abélard tot Zoroaster (1994). Para este artigo utilizo a tradução italiana organizada por Silvia Contarini e publicada sob título Miti e personaggi della modernità (1998).

${ }^{6}$ Vide também na referida obra, entre outros, Dom Quixote, Dom Juan, Fausto, Hamlet, e a belíssima análise da figura de Turandot como arquétipo feminino misantrópico.

${ }^{7}$ Para tal argumento sobre 0 afluxo literário na obra de Shakespeare, vide 0 completo BULLOUGH, 1960. verdadeiras motivações, fixa as ações deficientes em motivações falseadas, e se depara com a culpabilidade do pressentimento e da previsão obscura de um erro vital. A saída simbólica do mito, em sua significação de ordem psicológica, aponta para uma direção sensata da vida, "é o germe de uma orientação em direção ao sentido da vida" (DIEL, 1991, p. 21). Assim, mitologizar (ato de simbolização mítica e de sublimação ativa) é instaurar no campo de batalha dramática o antídoto contra a angústia culposa gerada pelo tormento da perda de harmonização entre as motivações íntimas e as ações. "Dado que os mitos simbolizam a vida e seu sentido, o tema inesgotável de que tratam os mitos na sua linguagem enigmática são: o desejo e suas transformações energéticas (exaltação ou harmonização).” (DIEL, 1991, p. 31).

Mesmo sem entrar no detalhamento conceitual de categorias próprias da hermenêutica e da exegese mitológica, vejamos alguns exemplos de como tais funções instauradoras do mito aparecem na cultura teatral e na dramaturgia moderna, trazendo referências apontadas pela excelente obra $D e$ Abelardo a Zoroastro de Léon Stapper, Peter Altena e Michel Uyen publicada originalmente em holandês. ${ }^{5}$ Os autores fazem um apanhado na história cultural e literária, identificando figuras e obras que, mesmo sem terem relações diretas entre si e não pertencerem a um "universo coerente e autônomo como o da antiguidade", constituem modelos culturais e mitos "depositários das certezas e sobretudo da inquietações do homem moderno" (1998, p. VII, trad. nossa). Nos limitemos, para o propósito deste artigo, somente à análise de uma das "figura teatrais" da dramaturgia ocidental trazidas pelos autores: Macbeth. ${ }^{6}$

A figura histórica de Macbeth, que reinou na Escócia de 1040 a 1057, é reinventada por William Shakespeare em The Tragedy of Macbeth(1606), seu último drama. A partir de uma série de incursões em obras literárias que vão das Chronicles of England, Scotland and Ireland (1587) de Raphael Holinshed, da Bíblia à Daemonologie (1597) do rei James $\mathrm{I}^{7}$, a fantasia mitopoética de Shakespeare faz da figura histórica do hábil e devoto soberano um indivíduo não confiável e titubeante, à merce das paixões, das predileções sobrenaturais e das ambições alheias, envolto numa atmosfera sinistra repleta de traições, sede de poder, mentiras e violência. $\mathrm{O}$ mitologema da competição masculina arquetípica é portado ao extremo sanguinoso. Macbeth é levado a agir mais por elementos externos do que pelas próprias emoções ou certezas interiores, acaba por se tornar uma vítima de paixões inconscientes ou ignoradas e, neste sentido, pode ser comparado a Édipo (STAPPER, 1998). Almas nervosas, infladas pela vaidade, vacilantes, que compensam sua inferioridade pela procura ativa de uma superioridade dominadora, pela ambição por um poder que se transformará na causa de sua derrota interior. Quando mata o Rei Duncan, Macbeth mata o "pai mítico de todos", o pai de todo homem, e, impulsionado pela ambição da esposa, mulher mítica devoradora, desposa os 
desejos terrestres irrefreáveis impregnados de violência. No mitologema da complementariedade dialética masculino-feminino (nos moldes de Adão e Eva), Macbeth e Lady Macbeth formam o "par fatal". Apesar de seu sucesso viril no campo de batalha, Macbeth é extremamente frágil e influenciável diante da mulher. É uma marionete em forma de soldado (conforme sugere Eugène Ionesco em sua versão de 1972), age mecanicamente fascinado pelo poder ilimitado. Macbeth morre pelo mesmo mecanismo irrefreável reproduzido pelos seus sucessores homicidas, que anunciam que piores tempos virão; Lady Macbeth enlouquece sucumbida pelo remorso tardio, pela culpabilidade que cela a angústia culposa do erro vital em transformar motivações íntimas em ações despropositais e trágicas. Shakespeare reinventa assim uma cadeia de mitologemas, dando-lhes movimento em forma de um mito sombrio de dialética fatal: a história de Macbeth - que ciclicamente se perpetuará na nossa cultura falocêntrica de combates competitivos e mortíferos entre os homens.

Mas para que tal obra prima mantivesse tal valência simbólica no decorrer do tempo, o seu substrato histórico, as referências de fatos de época e a psicologia situacional das tramas da tragédia, que se movem sempre nos limites compreensíveis e assimiláveis da consciência humana, não seriam suficientes. O poeta confere à obra um grau superior pelo seu modo visionário de elaboração de conteúdos simbólicos. A definição de Jung sobre tal modo de elaboração artística é aqui aplicável: "sua essência, estranha, de natureza profunda, parece provir de abismos de uma época arcaica, ou de mundos de sombra e de luz sobre-humanos" (JUNG, 1985, p. 78). A destruição de valores humanos, o choque emotivo e o despertar de pressentimentos inquietantes são ativados, de modo demoníaco e desarmônico, pela angústia do eterno caos, pela "terribilidade" da vivência mítica.

Esta rápida análise já nos é suficiente para ressaltar um aspecto essencial na problemática da dramaturgia criativa e do trabalho de "adaptações" de clássicos da mitologia moderna, como Macbeth: a historicidade e a atualização da fábula mítica e passional podem não bastar; ou melhor, podem simplesmente reduzir uma vivência visionária numa experiência representacional, numa série de figurações, num quebra-cabeças em que faltam peças importantes, num tour de passe-passe, num mero substitutivo (sintoma), perdendo-se o caráter original, intuitivo, transpessoal e mobilizador, o pleroma, da psicologia profunda e transcendente da obra. Ressalta-se, assim, a importância de o dramaturgo, o dramaturgista ou o ator-criador se apoderarem de figuras mitológicas no sentido de recriarem expressões visionárias, frutos de uma "observação íntima", de uma exploração intuitiva e de uma apreensão simbólica e atual da obra: "Para compreender seu sentido, é preciso permitir que ela nos modele, do mesmo modo que modelou o poeta. Compreenderemos então qual foi a vivência originária deste último. Ele 


\section{Urdimento}

${ }^{8}$ Material original de 1962, publicado em italiano por Ludwik Flaszen e Carla Pollastrelli em 2001; e no Brasil pela Perspectiva/SESC, 2007, com tradução de Berenice Raulino. tocou as regiões profundas da alma, salutares e libertadoras, onde o indivíduo não se segregou ainda na solidão da consciência, seguindo um caminho falso e doloroso." (JUNG, 1985, p. 93).

Todo mito, para que seja atualizado (presentificado), exige um grau de in-corporação da história e de "fisicalização" da narrativa.

No texto A Possibilidade do Teatro ${ }^{8}$, Jerzy Grotowski descreve alguns procedimentos adotados pelo Teatro das 13 Filas no trabalho com os arquétipos na dramaturgia criativa e afirma que a tarefa no trabalho sobre um texto concreto é:

destilar do texto dramático ou plasmar sobre a sua base o arquétipo, isto é, o símbolo, o mito, o motivo, a imagem radicada na tradição [...]. O arquétipo - como definido acima - é uma forma simbólica de conhecimento do homem sobre si mesmo, ou - se alguém preferir - de ignorância. Revelar por parte da encenação o arquétipo, a sua substância real, a sua essência, nos aproxima de fato do efeito que Broniewski caracterizou como "penetrar a fundo com a voz e com o corpo no conteúdo do destino humano”. (2007, pp. 50 e 51).

Tomando o cuidado em anunciar o seu precário background filosófico junguiano, o diretor polonês pontua uma série de figuras da mitologia antiga e moderna: Prometeu, arquétipo do homem-xamã que se entrega às potências demoníacas e graças a elas obtém o poder sobre a matéria; Winkelried, arquétipo do auto-sacrifício de sangue, herói suíço que deixou-se passar pelas lanças dos inimigos e com seu sacrifício abriu a estrada da vitória para seus companheiros; Twardowski, lendário bruxo e mago polonês do século XVI, o equivalente polonês de Fausto; Caim, arquétipo do mito bíblico, sobre o qual Grotowski trabalhou em sua "releitura" do texto romântico de Lord Byron.

Tais apropriações da mitologia na dramaturgia criativa eram conduzidas através de um procedimento típico que passou a ser conhecido, após a análise de T. Kudliński sobre a montagem de Caim, como "dialética da derrisão (sarcasmo) e da apoteose (divinização)": "a dialética da derrisão $e$ da apoteose consistia em criar um contraponto ao arquétipo poético por meio daquilo que é o seu substrato fisiológico, por meio do erotismo da esfera biológica, assimilando os atos de amor dos seres humanos ao espasmo dos pássaros ou dos insetos, através do movimento que pela associação inconsciente revela as suas fontes fisiológicas". (GROTOWSKI, 2007, p. 57).

Grotowski propunha a laicização e a "re-sacralização" do mito através do ataque ao "inconsciente coletivo" e da corporificação fisiológica do arquétipo, entendido como modelo-metáfora da condição humana, o objeto do mistério, 
assim como na pré-história do teatro, o ponto mágico de convergência coletiva do jogo e da cerimônia: "O arquétipo será revelado, compreendido na sua essência, se o atacamos, o colocamos em movimento, o fazemos vibrar, se o profanamos desnudando-o nos aspectos contraditórios, através de associações contrastantes e do choque de convenções." (2007, p. 52).

O pathos corporal, o choque dos opostos e das contradições, "a luta do indivíduo contra Deus", conduz a rebelião metafísica que demonstra a ingenuidade, a tragicidade e a redenção humanas, penetra "a fundo com a voz e com o corpo no conteúdo do destino humano" (BRONIEWSKI apud GROTOWSKI, 2007, p. 53); faz vibrar a cadeia de tabus, de convenções, as coisas sacras e o cortejo incessante de valores humanos, o rito, o cerimonial.

Como nos lembra Kerenyi, citado no início deste artigo, a mitologia é o movimento manifesto dado aos arquétipos (imagens primordiais) expressos em núcleos de significação estruturais: os mitologemas (palavra/ conceito que o mestre polonês não utiliza, mas que se aplica perfeitamente ao procedimento adotado). E, no que toca a mitologização teatral, será o rito da metamorfose corporal que dará o substrato e a fonte fisiológica para tal manifestação convergente.

Assim as funções simbólicas do corpo e do movimento, como formas primárias de organização da memória cultural, estão na base da recriação de um mito e de sua elaboração expressiva na arte da dramaturgia e no trabalho do ator: movimento intrapsíquico de transformação energética dos desejos e das motivações humanas em ações conflituais compartilhadas pelo rito teatral. Do mesmo modo que no mitologizar dos antigos ou no "cálculo psicológico" das terapias modernas, a função diretiva de espiritualizaçãosublimação teatral encontra, por uma via esclarecida e objetivada, e por participation mystique, a re-apresentação dos objetos desejados num percurso de conquista simbólica.

Mas tal processo pode não ser "bem sucedido" do ponto de vista sublimatório quando gera distrofias e digressões espirituais, quando tal função diretiva não vem a favor da espiritualização ativa, mas produz um estado de aculturação causado por forças imaginativas autorreferentes e por uma afetividade divagadora narcísica não voltada a uma real expressão e simbolização conectada com motivações pessoais, tradições culturais e crenças compartidas.

A positividade do trabalho do ator e da dramaturgia criativa, nesta perspectiva, nasce com a capacidade mitopoética em gerar imagens de significação que exprimam o desejo e o drama humanos como um antídoto contra o vazio do verbo e a solidão da consciência. 


\section{Urdimento}

\section{Referências bibliográficas}

BOECHAT, Walter. A mitopoese da psique: mito e individuação. Petrópolis: Vozes, 2008.

BUlloUGH, Geoffrey. Narrative and Dramatic Sources of Shakespeare. London: Routledge \& Kegan Paul, 1960.

CASSIRER, Ernst. Linguagem e mito. São Paulo: Perspectiva, 1985.

DIEL, Paul. O simbolismo na mitologia grega. São Paulo: Attar, 1991.

FLASZEN, Ludwik e POLLASTRELLI, Carla (org.). O teatro laboratório de Jerzy Grotowski 1959-1969: textos e materiais de Jerzy Grotowski e Ludwik Flaszen com um escrito de Eugenio Barba. São Paulo: Perspectiva/SESC, 2007.

JUNG, Carl Gustav. O espírito na arte e na ciência. Petrópolis: Vozes, 1985. Os arquétipos e o inconsciente coletivo. Petrópolis: Vozes, 2000.

KERENYI, Karl. Prolegomeni allo studio scientifico della mitologia. Torino: Boringhieri, 1983.

PATAI, Raphael. O mito e o homem moderno. São Paulo: Cultrix, 1974.

SANT'ANNA, Antonio Vargas. Apontamentos para o estudo da identidade artística. Revista Urdimento, UDESC: Florianópolis, v. 7, pp. 75-82, 2006.

STAPPER, Léon; ALTENA, Peter; UYEN, Michel. Miti e personaggi della modernità: dizionario di storia, letteratura, musica e cinema. Milano: Bruno Mondandori, 1994. 